\title{
Development of the composition of feed additives based on the developed algorithm, including the studied probiotic strains
}

\author{
Galina Zelenkova ${ }^{1, *}$, Alexey Zelenkov ${ }^{2,1}$, Natalia Lesovaya ${ }^{1}$, Antonina Pahomova ${ }^{3}$, and \\ Alexander Pakhomov ${ }^{4}$ \\ ${ }^{1}$ Don State Technical University, 344003, sq. Gagarina, 1, Rostov-on-Don, Russia \\ ${ }^{2}$ Ministry of Agriculture and Food of the Rostov region, 344010, Krasnoarmeyskaya st., 33, Rostov- \\ on-Don, Russia \\ ${ }^{3}$ Platov South-Russian State Polytechnic University (NPI), Novocherkassk, Russia \\ ${ }^{4}$ Don State Agrarian University, 346493, o. Persianovsky, Russia
}

\begin{abstract}
The aim of the study was to develop an algorithm for compounding feed mixtures with the inclusion of probiotic strains. The authors have developed the basic principles underlying the modeling of feed additive formulations. However, the introduction of viable cells of beneficial microorganisms (probiotics) into the feed significantly increases the requirements for the level of design of feed products. Thus, the article describes the basic principles of the algorithm for designing feed products for poultry. A technological scheme for combining the components of the supplement and probiotic drugs has been developed. In accordance with the developed algorithm, the effect of such an active component of the feed additive as bentonite on the growth and survival of the target probiotic strains was tested. Feed mixtures with the inclusion of the probiotic strains under study were tested in the experiment on broiler chickens. The result of the study was positive results of the productivity of the raised poultry in the experimental groups.
\end{abstract}

\section{Introduction}

Let's remember the definition of Probiotics-these are living microorganisms.

Probiotics include lactobacilli, bifidobacteria, lactic acid streptococcus, yeast fungi, etc. These bacteria lower the acidity $(\mathrm{pH})$ in the intestines of animals and poultry, which has a healing effect, since pathogens prefer an alkaline environment for their development $(\mathrm{pH}$ 6.0 and higher).

It is known that most of the microorganisms that inhabit the intestine are safe and do not cause diseases, but there is a constant competition between bacteria of different species for space and nutrients. Harmless and opportunistic bacteria inhibit the growth and reproduction of each other. However, temperature stress, changes in diet, rearrangements, and vaccinations inevitably affect the microbiological balance in the gastrointestinal tract

\footnotetext{
* Corresponding author: zelenkovalex@rambler.ru
} 
and shift it towards pathogenic or conditionally pathogenic microflora. With such disorders, the intestinal balance can be restored with the help of favorable bacteria, additionally introduced with food. The principle of replacing undesirable bacteria with competing beneficial ones is known as the principle of probiotics.

There are spore-forming probiotics that are resistant to digestive juices and gastrointestinal enzymes. They do not break down, pass through the stomach and reach the vital parts of the intestine. In addition, spore-forming probiotics can withstand high temperatures and pressure, which allows them to be used in the granulation or extrusion of feed.

Today, a wide range of various feed additives, preparations, vitamin and mineral premixes has been developed for domestic animals and poultry, but the task of designing effective probiotic preparations for veterinary use, optimized for the animal body and specific application tasks, has not yet been solved.

\section{Materials and Methods}

\subsection{Algorithm for constructing the composition of feed additives with the inclusion of the studied probiotic strains}

The distribution of feed containing probiotics is one of the most attractive trends in modern animal husbandry for consumers. The introduction of a live component makes the feed not only more effective, but also reduces the content of toxic components, making animal products more environmentally friendly.

However, the introduction of viable cells of beneficial microorganisms into the feed significantly increases the requirements for the level of feed design, which in turn forces the development of new, unusual algorithms for such design for zootechnics.

First of all, the development of feed additives with the inclusion of probiotic strains should be carried out only taking into account the specific application (type of animal of agricultural significance) and the extent to which the studied microorganisms and the substrate for microbial fermentation are suitable for this animal. The most important issue in this regard is the interaction of the living component with the inanimate one. At a minimum, substances that are part of probiotic feeds and feed additives should not inhibit the growth of target microorganisms. The ideal option is the ability to stimulate their growth or prebiotic activity.

Another important point is the absence of the above-mentioned substances of mutagenic activity not only for animal husbandry objects, but also for probiotic microorganisms. The accumulation of antibiotic resistance mutations in the target strains can turn them into a depot of the corresponding genes for saprophytic and pathogenic microflora, which can, in turn, reduce the probiotic effect to its opposite.

Thus, according to modern theoretical concepts, the algorithm for developing a probiotic supplement includes significant variables (modules), such as:

1) target microorganism (or a combination of microorganisms)

2) type of growth substrate

3) formation of the composition of the feed additive, based on the physiological needs of the intended object.

4) technological parameters for obtaining feed additives:

* fermentation mode - this module consists of several components, including time, temperature, humidity, water activity

* drying

* granulation/extrusion 
* packaging and storage

5) product quality confirmation:

* testing the effect of the supplement components on the growth and survival of the target strains.

* replacement of toxic components for the target strains with non-toxic components.

* correction of the additive formulation in the direction of increasing the content of probiotic components.

* testing the mutagenicity of the additive components for the target strains.

* exclusion of mutagenic components.

As a result of the research conducted during the current project, a library of probiotic microorganisms and their fundamental characteristics will be created, on the basis of which the developed algorithm aimed at individualizing the design of probiotic veterinary drugs will be improved and detailed. Work on identifying and optimizing the algorithm modules will continue.

\section{Results}

\subsection{Development of the composition of feed additives based on the developed algorithm}

\section{Target microorganisms}

Probiotics are attractive for use in animal husbandry and poultry farming due to their ability to stimulate growth and prevent disease in animals and poultry. The developed feed additives will use two strains of probiotic bacteria Bacillus subtilis and Bacillus amyloliquefaciens, isolated and genetically characterized. Both strains have shown themselves as probiotics with antioxidant and DNA-protective activity and have a stimulating effect on feed conversion, poultry growth, egg production and egg fertilization. Probiotic strains of Bacillus subtilis and Bacillus amyloliquefaciens protect the mitochondrial DNA of chickens from damage, which is one of the markers of reduced cellular aging. Thus, the strains Bacillus subtilis and Bacillus amyloliquefaciens can be considered as a reference strain with complex activity. The expected effects of the inclusion of the probiotic strains studied in the composition of feed additives will be both tactical (suppression of pathogens, immunomodulation, improvement of metabolism, etc.) and strategic (modulating and maintaining normal microbiota).

Type of growth substrate

According to our data, in order to achieve a sufficient titer of the studied probiotic strains in the feed additive, the best prebiotic activity is provided by soy processing products and sugar/beet industry waste. Currently, the study of various growth substrates is continuing, with special attention to the type of animal to which the probiotics will be delivered. So, in particular, work has already been carried out on the use of duckweed as a feed substrate for the probiotic bacilli under study, since duckweed is used as feed for waterfowl and for fish.

Formation of the composition of the feed additive, based on the physiological needs of the intended object

Feed preparations created on the basis of biologically active substances and compounds are designed to maintain high poultry productivity, improve feed consumption and assimilation, preserve the quality of feed, remove toxins and maintain a high level of natural resistance. Biologically active feed additives may contain essential amino acids and enzymes, vitamins, mineral supplements, antioxidants, mycotoxin inactivators, probiotics, adsorbents, aromatic and flavoring additives, and growth biostimulants. All feed products 
must be of good quality, meet the existing standards for safety indicators and the needs of animals and poultry in nutrients and biologically active substances.

The intensification of the technology of industrial poultry farming, the growth of the genetic potential of modern poultry crosses dictate the need to complicate the composition and increase the norms of the introduction of biologically active substances. Rich in nutrients and biologically active substances, the compound feed intensifies the metabolism, the biosynthesis of the necessary compounds-metabolites and their transition to the egg, allows you to use the genetic potential of the productivity of modern egg crosses of laying hens.

An insufficient amount of biologically active substances and their incorrect ratio often leads to a violation of the processes of hematopoiesis, protein and carbohydrate metabolism, a violation of the functions and structure of the gastrointestinal tract, liver, kidneys and other organs, resulting in reduced growth energy and productivity, increased morbidity and reduced resistance of the body of laying hens.

Testing the effect of the additive components on the growth and survival of the target strains

Despite the fact that the technological scheme involves combining clay powder and probiotic preparations immediately before feeding the bird, according to the developed algorithm, it is necessary to test the effect of such an active component of the feed additive as bentonite on the growth and survival of the target strains.

Two variants of bentonite were used: pure bentonite and bentonite after being used as a filter for sunflower oil purification.

To determine the number of microorganisms in bentonite, $1 \mathrm{~g}$ of the test powder was ground in $10 \mathrm{ml}$ of sterile water until a homogeneous suspension was formed, from which a series of successive dilutions was prepared and then sown on a solid culture medium LB and on soy agar. Incubated at a temperature of $37^{\circ} \mathrm{C}$ for 1 day.

To determine the toxicity of bentonite to bacteria of the genus Bacillus, both types of bentonite were sterilized at a temperature of $120^{\circ} \mathrm{C}$ for 20 minutes. Then each of the bentonite types was ground in sterile water $(2 \mathrm{ml}$ of water per $1 \mathrm{~g}$ of bentonite) until a homogeneous suspension was obtained, which was subsequently mixed with soy agar at a concentration of $1,2.5,5,10,20,50 \%$. The resulting nutrient medium was poured into Petri dishes, the control was soy agar without the addition of bentonite.

Suspensions of Bacillus subtilis (MacFarland turbidity 0.7, corresponding to about $2 \times 10^{8} \mathrm{CFU} / \mathrm{ml}$ ) or Bacillus amyloliquefaciens (MacFarland turbidity 1.9 , corresponding to about $5 \times 10^{8} \mathrm{CFU} / \mathrm{ml}$ ) were prepared. A number of successive dilutions were prepared from the obtained suspensions and seeding was performed from the fifth and sixth dilutions. The cups were incubated for 1 day at a temperature of $36^{\circ} \mathrm{C}$ or $42^{\circ} \mathrm{C}$. Next, the grown colonies from the fifth breeding were counted.

Both types of bentonite were seeded with different types of bacteria at concentrations of $5 \times 10^{2}$ and $3 \times 10^{2}$, respectively, for pure bentonite and bentonite after oil filtration. The bacteria had different colony forms, and belonged to different Gram-positive and Gramnegative species.

Data on the effect of bentonite on bacteria of the genus Bacillus are presented in Tables 1 and 2 .

Table 1. Effect of bentonite in different concentrations on the growth of $B$. subtilis, number of colonies per cup.

\begin{tabular}{|c|c|c|c|c|}
\hline \multirow{2}{*}{ Concentration, \% } & \multicolumn{2}{|c|}{ Pure Bentonite } & \multicolumn{2}{c|}{$\begin{array}{c}\text { Bentonite after sunflower oil } \\
\text { filtration }\end{array}$} \\
\cline { 2 - 5 } & $36^{\circ} \mathrm{C}$ & $42^{\circ} \mathrm{C}$ & $36^{\circ} \mathrm{C}$ & $42^{\circ} \mathrm{C}$ \\
\hline 0 & $23 \pm 5$ & $22 \pm 2$ & $26 \pm 3$ & $19 \pm 3$ \\
\hline 1 & $21 \pm 4$ & $20 \pm 4$ & $20 \pm 2$ & $23 \pm 5$ \\
\hline
\end{tabular}




\begin{tabular}{|c|c|c|c|c|}
\hline 2.5 & $20 \pm 3$ & $24 \pm 3$ & $12 \pm 5^{*}$ & $13 \pm 6^{*}$ \\
\hline 5 & $25 \pm 3$ & $24 \pm 5$ & $0^{*}$ & $0^{*}$ \\
\hline 10 & $26 \pm 4$ & $21 \pm 4$ & $0^{*}$ & $0^{*}$ \\
\hline 20 & $21 \pm 5$ & $27 \pm 5$ & $0^{*}$ & $0^{*}$ \\
\hline 50 & $18 \pm 3$ & $24 \pm 3$ & $0^{*}$ & $0^{*}$ \\
\hline
\end{tabular}

* significant difference from the control $(\mathrm{p}<0.05)$

Table 2. Effect of bentonite in different concentrations on the growth of $B$. amyloliquefaciens number of colonies per cup.

\begin{tabular}{|c|c|c|c|c|}
\hline Concentration, \% & \multicolumn{2}{|c|}{ Pure Bentonite } & \multicolumn{2}{c|}{$\begin{array}{c}\text { Bentonite after sunflower oil } \\
\text { filtration }\end{array}$} \\
\cline { 2 - 5 } & $36^{\circ} \mathrm{C}$ & $42^{\circ} \mathrm{C}$ & $36^{\circ} \mathrm{C}$ & $42^{\circ} \mathrm{C}$ \\
\hline 0 & $48 \pm 3$ & $51 \pm 5$ & $44 \pm 6$ & $47 \pm 3$ \\
\hline 1 & $50 \pm 4$ & $50 \pm 3$ & $40 \pm 4$ & $45 \pm 3$ \\
\hline 2.5 & $51 \pm 6$ & $45 \pm 6$ & $24 \pm 6^{*}$ & $27 \pm 5^{*}$ \\
\hline 5 & $46 \pm 3$ & $40 \pm 5$ & $0^{*}$ & $0^{*}$ \\
\hline 10 & $54 \pm 2$ & $53 \pm 4$ & $0^{*}$ & $0^{*}$ \\
\hline 20 & $47 \pm 5$ & $51 \pm 4$ & $0^{*}$ & $0^{*}$ \\
\hline 50 & $43 \pm 4$ & $49 \pm 3$ & $0^{*}$ & $0^{*}$ \\
\hline
\end{tabular}

* significant difference from the control $(\mathrm{p}<0.05)$

From the presented data, it can be concluded that pure bentonite had no effect on the growth of the studied bacteria. Even when bentonite was added to the medium in high concentrations, no reduction in bacterial survival was observed.

Bentonite obtained from filters after cleaning sunflower oil had a depressing effect on the growth of bacteria, both Bacillus amyloliquefaciens and Bacillus subtilis. If at a one percent concentration of such bentonite in the medium, no significant differences in bacterial growth from the control were observed, then already at an increase in the concentration to $2.5 \%$, a decrease in survival was noted by $47-50 \%$ for Bacillus amyloliquefaciens and $41-48 \%$ for Bacillus subtilis. A further increase in the concentration of spent bentonite completely suppressed the growth of bacteria.

Obviously, this difference in the action of bentonite is associated with the processes occurring in the oil filtration process. It can be assumed that the growth of bacteria suppresses the remaining sunflower oil in the bentonite, but this is unlikely.

On the other hand, bentonite is able to adsorb various substances on itself. It is logical to assume that in the process of oil purification, toxic substances are deposited on the bentonite and accumulate in it. This assumption is more likely, but requires further research.

Conclusion: pure bentonite is considered by us as a growth substrate for probiotics intended for use in industrial and farm poultry farming. It is proposed to study the possibility of using spent bentonite, after purification of sunflower oil, as a carrier for probiotic crops aimed at use in poultry farming, taking into account the use of spent bentonite in small concentrations (no more than 1\%).

Spent and pure bentonite will be studied both as carriers for probiotics of the extended group (including Lactobacillus), and as growth substrates for probiotic cultures.

The developed algorithm for designing probiotic additives assumes, as part of the module for confirming the quality of the resulting product, in the event of a negative result, the replacement of toxic components for the target strains with non-toxic ones.

It may also be necessary to adjust the formulation of the supplement in the direction of increasing the content of probiotic components.

Study of the effects of probiotics on the body of birds 
The next stage of our research was the study of the effects of probiotics on the body of birds as a result of scientific and economic experience. 5 groups were formed: one control group and four experimental groups. Each group had 40 goals. The chickens of the control and experimental groups were provided with the same conditions of maintenance in accordance with zoohygienic requirements, feeding was carried out with a full-fledged compound feed with the introduction of the test probiotic in a dosage of $1 \%$ of the weight of the diet.

The scheme of scientific and economic experience is presented in Table 3.

Table 3. Scientific and economic experience.

\begin{tabular}{|c|c|c|c|}
\hline \multirow[t]{2}{*}{ Group } & \multirow[t]{2}{*}{ Number, heads } & \multicolumn{2}{|c|}{ Test probiotic preparation for the main diet } \\
\hline & & probiotic & injection dosage \\
\hline \multicolumn{4}{|c|}{ Cross broilers Cobb-500 } \\
\hline Control & 40 & - & - \\
\hline I experienced & 40 & KATMIRA & $1 \%$ from the weight of the diet \\
\hline II experienced & 40 & KB 16 & $1 \%$ from the weight of the diet \\
\hline III experienced & 40 & KB 41 & $1 \%$ from the weight of the diet \\
\hline IV experienced & 40 & KB 54 & $1 \%$ from the weight of the diet \\
\hline
\end{tabular}

During the experiment, the following indicators were taken into account: the live weight of chickens (weekly weighings), the safety of livestock and the causes of death, feed consumption. When probiotics were included, the safety of chickens during the experiment period (30 days) was higher in the experimental groups compared to the control. Growing broilers on one complete feed (control) allowed us to obtain an average daily increase in live weight of $46.05 \mathrm{~g}$, with the addition of probiotics higher by $7.0-11.0 \%$ than in the control.

\section{Conclusions}

As a result of the research, an algorithm for obtaining new feed additives for poultry has been developed. Control modules have been installed that help to create the most productive and safe feed additive with the inclusion of probiotic drugs. The components of feed additives were also tested with the inclusion of the probiotic strains under study. The developed feeding parameters were tested. As a result of the studies, positive results were obtained in groups of experimental chickens receiving feed additives with the studied probiotic strains included.

\section{References}

1. G.A. Zelenkova, I.F. Gorlov, Fodder bentonite for farm animals and a bird (ekobentokorm) TU 9283-199-10514645-13-2013 specifications (2013) URL: https://www.elibrary.ru/item.asp?id=23201318

2. S. Halász, V. Fedorchuk et al., E3S Web of Conferences, 210, 11003 (2020)

3. G. Ciurescu, M. Dumitru, A. Gheorghe, A.E. Untea, R. Drăghici, Poultry science, 99, 11, P. 5960-5971 (2020)

4. A. Zelenkov, A. Ermakov, G. Zelenkova et al., E3S Web of Conferences 135, 01088 (2019)

5. A. Pahomova, S. Halász, A. Pakhomov et al., E3S Web of Conferences 217, 06002 (2020)

6. V. Clavijo, M.J.V. Flórez, Poultry science 97, 3, P. 1006-1021 (2018) 
7. A. Zelenkov, G. Zelenkova, S. Tresnitskii et al., E3S Web of Conferences 217, 09010 (2020)

8. V. Berikashvili, K. Sokhadze, E. Kachlishvili, V. Elisashvili, ML. Chikindas. Probiotics Antimicrob Proteins 10(4), 755-761 (2018) doi:10.1007/s12602-017-9371-x.

9. A. Zelenkov, A. Ermakov, G. Zelenkova et al., IOP Conf. Series: Earth and Environmental Science 403 (1), 012020 (2019)

10. S.C. Ricke, S.I. Lee, S.A. Kim, S.H. Park, Z. Shi, Poultry science, 99, 2, 670-677 (2020)

11. A. Zelenkov, G. Zelenkova, A. Ermakov et al., E3S Web of Conferences 164, 06032 (2020)

12. A. Pahomova, A. Pakhomov et al. Vitamin and mineral adsorption food additives for poultry and the method of its application (A23K 50/70, A23K 20/158, A23K 20/174) (2016) URL: https://www.elibrary.ru/item.asp?id=37832316

13. R. Khan, S. Naz, World's Poultry Science Journal 69 (3), 621-632 (2013)

14. P. Surai, I. Kochish, M. Kidd, Animal Feed Science and Technology 260, 1114339 (2020)

15. D. Bederska-Lojewska, S. Swiatkiewicz, B. Muszyniska, Animal Feed Science and Technology 230, 59-69 (2017)

16. O. Tyukavkina, S. Plavinsky, I. Tatarenko et al. E3S Web Conferences EBWFF-2020, 01019 (2020)

17. A. Khabirov, F. Khaziakhmetov, V. Kuznetsov et al. Indian Journal of Pharmaceutical Education and Research 54 (4), 1046-1055 (2020)

18. T. Lenkova, I. Nikonov, Y. Kuznetsov et al. International Journal of Innovative Technology and Exploring Engineering 9 (1), 2452-2454 (2019) 